DOI: 10.12731/wsd-2018-1-64-74

УДК 543.42:543

\title{
НУКЛЕАЦИЯ И ФОРМИРОВАНИЕ ГАЗОГИДРАТОВ В ЗАВИСИМОСТИ ОТ ФИЗИКО-ХИМИЧЕСКИХ СВОЙСТВ НЕФТЕЙ
}

\author{
Сваровская Л.И., Манаков А.Ю., Алтунина Л.К.
}

Образование газогидратных пробок в промысловых трубопроводах является одним из значимых осложняющих факторов при добыче нефти в холодных регионах и на шельфе. Меры, необходимые для предотвращения образования этих пробок, усложняют и удорожают добычу нефти. Газовые гидраты представляют кристалль, где молекулы газа заключены в каркас молекул воды. Природные газогидраты образуются при высоком давлении и низкой температуре, что типично условиям добычи нефти в холодном подводном окружении.

Нами проведено комплексное исследование сырых нефтей разных месторождений Западной Сибири и их водных эмульсий, приготовленных в кониентрации 50\%. Технически важные характеристики, такие как вязкость, плотность, температура застьвания, групповой состав рассматривались для нефтей и эмульсий воды в нефти. В работе раздельно изучалось влияние состава нефтей на формирование нефте-смачиваемых гидратов.

Эмульсии исследованы в модельном эксперименте нуклеачии и образования газогидратов. Нефть ҮиТ, из всех исследуемых, проявила положительную реакцию нуклеации и формирования газогидратов. Важным показателем склонности к нуклеачии и формированию гидратов является уровень биодеградаџии сырой нефти. Прочесс биодеградащии в условиях месторождения оказывает значительное влияние на качество сырой нефти с точки зрения её химического состава и физических свойств.

Для выявления функииональных групп конкретных молекулярных структур, определяющих уровень биодеградации, использован метод ИК-Фурье спектроскопии. Анализ ИК-Фурье спектров нефтей показал, что полосы поглощения насыщенных алифатических углеводородов (1465-1377 $\left.\mathrm{cm}^{-1}\right)$, ароматических (1610 $\left.\mathrm{cm}^{-1}\right)$ и карбонильных групп карбоновой кислоты $\left(1710 \mathrm{~cm}^{-1}\right)$ доминируют во всех спектрах исследуемьхх нефтей. 
Полевые наблюдения показали, что некоторые потоки воды, газа и сырой нефти не образуют гидратов (hydrateplugs) в прочессе добычи нефти, даже при работе в пределах термодинамических условий образования гидратов. Результаты позволяют предположить, что способность нефтей формировать газогидратные пробки может быть связана с продуктами метаболизма, которые образуются при биодеструкиии углеводородов нефти.

Ключевые слова: состав нефтей; ИК-спектры; биодеструкиия, эмульсия воды в нефти; нуклеаџия; газогидраты.

\section{NUCLEATION AND FORMATION OF GAS HYDRATES DEPENDING ON THE PHYSICAL AND CHEMICAL PROPERTIES OF OILS}

\section{Svarovskaya L.I., Manakov A.Yu., Altunina L.K.}

Formation of gas hydrate plugs in oilfield pipelines is one of the major complicating factors for oil recovery in cold regions and on shelf. Hydrate prevention in the pipelines makes oil recovery more complex and expensive. Formation of gas hydrate plugs in oilfield pipelines is one of the major complicating factors for oil recovery in cold regions and on shelf. Hydrate prevention in the pipelines makes oil recovery more complex and expensive.

A complex study of the oils of different fields in Western Siberia and their emulsions prepared at a concentration of $50 \%$ was carried out. Technically important characteristics, such as viscosity, density, pour point, and group composition were considered for native oils and their emulsions. In the paper the influence of the oil composition on formation of oil-wet hydrates.

Water-in-oil emulsions of the investigated oils were applied in the model experiment of nucleation and formation of gas hydrates. Oil YuT, of all the studied, showed a positive reaction of nucleation and formation of gas hydrates. The level of biodegradation of crude oil is an important indicator of nucleation and formation of hydrates. The process of biodegradation in the field conditions has a significant impact on the quality of crude oil in terms of its chemical composition and physical properties. IR Fourier spectroscopy was used to identify functional groups of specific molecular structures, that determine the level of biodegradation. Analysis of the FTIR spectra of oils showed that: absorption bands of saturated aliphatic hydrocarbons $\left(1465-1377 \mathrm{~cm}^{-1}\right)$, 
aromatic $\left(1610 \mathrm{~cm}^{-1}\right)$ and carbonyl groups of carboxylic acid $\left(1710 \mathrm{~cm}^{-1}\right)$ dominate in all spectra of investigated oils.

Field observations have shown that some streams of water, gas and crude oil do not form gas hydrate plugs during petroleum production even when operating within thermodynamic conditions for hydrate formation. The results suggest that the ability of oils to form gas hydrate plugs can be associated with metabolic products that are formed during biodegradation of petroleum hydrocarbons.

Keywords: oil; emulsions Water-in-oil; nucleation; gashydrates.

\section{Введение}

Газовые гидраты представляют собой класс клатратных твердых соединений в которых каркас, образованный молекулами воды, заполнен газами либо легколетучими жидкостями [1]. Газогидраты в природных условиях образуются при высоком давлении и низкой температуре. В нефтяных дисперстных системах формирование гидратов происходит при реакции растворенного в нефти попутного газа с эмульгированной в нефти водой $[2,3]$. Образование газогидратных пробок в промысловых трубопроводах является одним из значимых осложняющих факторов при добыче нефти в холодных регионах и на шельфе. Состав добываемой сырой нефти, её физико-химические свойства могут влиять на образование гидратов и формирование гидратных пробок $[4,5]$. Некоторые природные компоненты, содержащиеся в нефтях, выступают в качестве кинетических ингибиторов гидратообразования, (KI) и анти-агломерирующих агентов (АА), которые замедляют зародышеобразование гидратной фазы, предотвращают слипание гидратных частиц между собой и блокирование трубопровода $[6,7]$. Предполагается, что действие как синтетических, так и природных АА и КІ связано с их адсорбцией на поверхности гидратных частиц. Поскольку групповой и компонентный состав нефтяных систем определяют их свойства и соответствующие технологические процессы, большое внимание уделяется комплексному изучению нефтей [8]. Теория нуклеации в приложении к газовым гидратам подробно рассмотрена в работе [9]. В комплексных работах по изучению нефтей успешно используется метод инфракрасной спектроскопии (ИК-), который характеризуется производительностью, высокой точностью и позволяет изучать объекты малой прозрачности, что чрезвычайно важно при работе с нефтями [10 ].

Поскольку нефть является сложной системой, состоящей из сотен отдельных химических соединений, её ИК-спектр есть результат наложения индивидуальных соединений и функциональных групп [11]. Для характе- 
ристики нефтей наибольший интерес представляют спектральные коэффициенты (С) области поглощения алканов $\left(725 \mathrm{~cm}^{-1}\right)$, метильных $\left(1377 \mathrm{~cm}^{-1}\right)$, метиленовых $\left(1465 \mathrm{~cm}^{-1}\right)$ групп, ароматических $\left(1610 \mathrm{~cm}^{-1}\right)$ и кислородсодержащих (1710 $\left.\mathrm{cm}^{-1}\right)$ соединений. Очевидно, что физико-химические свойства нефтей, их групповой и компонентный состав, определяющие свойства и поведение сложных нефтяных систем, требуют комплексного подхода при изучении последних [12-14].

Причиной нуклеации и образования гидратов в водонефтяных эмульсиях служит прорастание кристаллов между каплями эмульсии в результате снижения механической прочности среды, что связано с присутствием кислородсодержащих соединений. Известно, что капли воды в нефтяных эмульсиях покрыты адсорбционной оболочкой из тяжелых компонентов нефти, которые обеспечивают устойчивость эиульсии и влияют на нуклеацию гидратов $[15,16]$.

Цель работы: комплексное исследование образцов нефти и установления некоторых причин нуклеации и образования газогидратов в зависимости от свойств нефтей и их эмульсий.

\section{Материалы и методы исследования}

В настоящей работе применялся набор из семи легких нефтей, отобранных на разных месторождениях Западной Сибири. Нефти обозначены, как YuT, VEg, Vch, Ger, Svt, Vh, Mam. Плотность нефтей определяли методом в соответствии с ГОСТ 189995.1-73 «Жидкие химические продукты. Методы определения плотности». Вязкость измеряли на реометре RheoStress 600 (НАAKЕ) с помощью коническо-пластинчатого измерительного блока в стационарных условиях при $20^{\circ} \mathrm{C}$ и атмосферном давлении.

«Температуру замораживания» (Т3) или температуру застывания нефтей измеряли в соответствии с ГОСТ 20287-91 на основе определения точки температуры, при которой нефть перестает двигаться при охлаждении с заданной скоростью.

ИК - Фурье спектры нативных нефтей снимали на инфракрасном спектрометре Nicolet IS10 корпорации Thermo Ficher Scientific (США). Параметры анализа ИК-Фурье: разрешение $4 \mathrm{~cm}^{-1}$, число сканов пробы и спектров сравнения 64, диапазон сканирования $4000-400 \mathrm{~cm}^{-1}$. По данным оптической плотности полос поглощения разных функциональных групп рассчитывали спектральные коэффициенты (C) для характеристики нефтей.

Принципиальная схема установки для исследования процессов образования гидрата метана из эмульсий воды в нефтях рассмотрена в работе 
[17]. Для каждой из эмульсий, нуклеация гидрата метана исследована на 24 образцах при давлении метана около 12 МПа. Температура в ходе эксперимента линейно понижалась со скоростью $0.14^{\circ} \mathrm{C} /$ мин от комнатной до $-14^{\circ} \mathrm{C}$, далее образцы нагревались с той же скоростью. Образование гидрата и льда регистрировалось по экзотермическим эффектам на линии охлаждения, плавление льда и разложение гидрата - по эндотермическим эффектом на линии нагрева. Длительность эксперимента определялась скоростью охлаждения- нагрева и составляла около 9 часов. Образование гидрата и льда регистрировались по скачкам температуры. Ошибки измерения температуры и давления составляла от $\pm 0.2^{\circ} \mathrm{C}$ до $\pm 0.25 \%$ от измеряемой величины, соответственно.

\section{Результаты и их обсуждение}

Сравнительный физико-химический анализ образцов нефтей, отобранных из добывающих скважин месторождений Западной Сибири, приведен в табл. 1.

Таблица 1.

Физико-химический анализ и групповой состав нефтей

\begin{tabular}{|c|c|c|c|c|c|c|c|c|}
\hline \multirow{2}{*}{\multicolumn{2}{|c|}{$\begin{array}{c}\text { Образцы } \\
\text { нефтей } \\
\rho, \text { г/см}{ }^{3}\end{array}$}} & \multicolumn{3}{|c|}{$\begin{array}{c}\text { Физико-химические } \\
\text { данные }\end{array}$} & \multicolumn{4}{|c|}{ Групповой состав, \%мас } \\
\hline & & \multirow{2}{*}{$\begin{array}{c}\eta, \text { мПа.с } \\
0.816\end{array}$} & \multirow{2}{*}{$\frac{\mathrm{T} 3,{ }^{\circ} \mathrm{C}}{6.13}$} & \multirow{2}{*}{$\begin{array}{l}\text { пара- } \\
\text { фины } \\
-30\end{array}$} & \multirow{2}{*}{$\begin{array}{c}\text { смолы } \\
0.9\end{array}$} & \multirow{2}{*}{$\begin{array}{c}\begin{array}{c}\text { асфаль- } \\
\text { тены }\end{array} \\
17.2\end{array}$} & \multirow{2}{*}{$\begin{array}{c}\begin{array}{c}\text { масляная } \\
\text { фракция }\end{array} \\
0\end{array}$} & \multirow[b]{2}{*}{92.4} \\
\hline 1 & YuT & & & & & & & \\
\hline 2 & VEg & 0.834 & 23.1 & -13 & - & 14.6 & 0.1 & 85.3 \\
\hline 3 & Vch & 0.858 & 19.3 & -43 & 2.3 & 19.7 & 0.1 & - \\
\hline 4 & Ger & 0.863 & 25.1 & +6 & 5.6 & 5.1 & 2.2 & - \\
\hline 5 & Svt & 0.867 & 17.5 & -16 & 1.9 & 15.7 & 1.5 & 87.8 \\
\hline 6 & $\mathrm{Vh}$ & 0.879 & 22.7 & -1.5 & 2.66 & 7.7 & 2.6 & 89.7 \\
\hline 7 & Mam & 0.879 & 30.25 & -5 & 2.31 & 8.9 & 1.7 & 89.4 \\
\hline
\end{tabular}

В выборке нефтей существует отчетливый линейный тренд - увеличение ТЗ с падением концентрации асфальтенов и увеличением содержания смол. Температура застывания (Т3) - важная характеристика, которая во многом определяет технические процессы добычи и переработки нефти. Известно, что высокое содержание парафинов обеспечивает повышенную T3, как например, нефть Ger (табл.1). Самую низкую T3 $-43^{\circ} \mathrm{C}$ определена для нефти Vch при концентрации парафинов 2.3 мас \%. Низкая температура застывания $-30^{\circ} \mathrm{C}$ определена также для нефти YuT, где содержание 
смол - 17.2; парафинов 0.9 мас \%, Нефть ҮuТ также характеризуется самой низкой вязкостью и плотностью по отношению к исследуемым образцам нефтей (табл. 1). Отметим, что выявить прямую линейную зависимость ТЗ от концентрации смол-асфальтенов не удалось именно из-за многокомпонентности нефтяной системы.

Для характеристики различных функциональных групп, нефти анализировали методом ИК-спектрометрии. В целом, полосы поглощения (п.п.) метиленовых и метильных групп (1465-1377 $\left.\mathrm{cm}^{-1}\right)$, ароматических углеводородов $\left(1600 \mathrm{~cm}^{-1}\right)$ и карбонильных соединений $\left(1700 \mathrm{~cm}^{-1}\right)$ доминируют во всех спектрах нефтей. Для примера на рис. 1. приведены спектры нефтей YuT и VEg, где определены практически все характеристические п.п. основных функциональных групп.

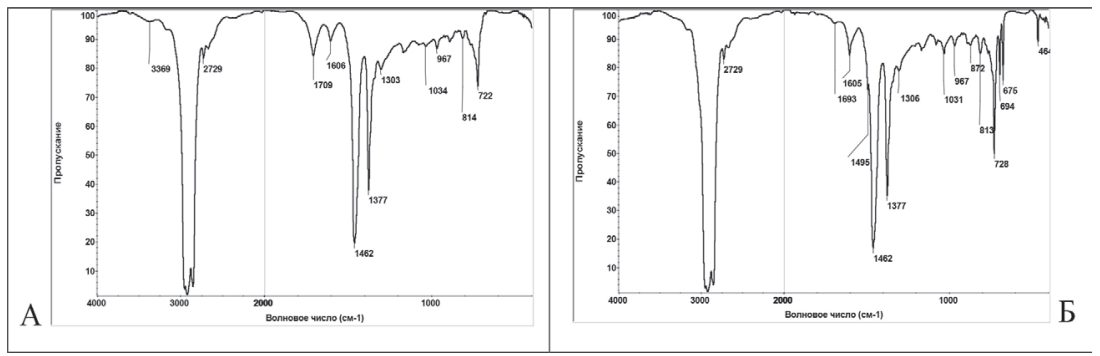

Рис. 1. ИК - спектры нефтей YuT (А) и VEg (Б)

При рассмотрении ИК - спектров наибольший интерес представляют спектральные коэффициенты, рассчитанные по отношению оптических плотностей характеристических полос поглощения различных структур, которые индивидуальны для каждой нефти (табл. 2). Показатели спектральных коэффициентов нефтей - вариабельны. Определенные закономерности подобраны только для нефти YuT, где показатели коэффициентов $\mathrm{C}_{2}, \mathrm{C}_{4}, \mathrm{Cp}$ и Со имеют максимальные значения. Коэффициенты $\mathrm{C}_{1}$ и $\mathrm{C}_{3}$ для YuT, отражающие содержание ароматических соединений (1600 см1), имеют самые низкие значения в сравнении с другими нефтями (табл. 2). Следовательно, можно сделать вывод, что при максимальном коэффициенте окисленности $\left(\mathrm{C}_{\mathrm{o}}=0.12\right)$ и минимальной плотности $\left(\rho=0.816\right.$ г $\left.\mathrm{cm}^{3}\right)$ нефть ҮuТ более биодеградирована по отношению к остальным нефтяным системам.

Исследуемые нефтяные системы отличаются малым содержанием ароматических углеводородов (п.п. $1600 \mathrm{~cm}^{-1}$ ) и кислородсодержащих 
соединений $\left(1710 \mathrm{~cm}^{-1}\right)$, что определило низкие значения коэффициентов ароматичности и окисленности. Перечисленный набор нефтей был использован для приготовления водонефтяных эмульсий в соотношении вода/нефть 1:1 в эксперименте по образованию газогидратов (табл. 3).

Таблица 2.

Спектральные коэффициенты нефтей

\begin{tabular}{|l|c|c|c|c|c|c|c|}
\hline \multirow{2}{*}{$\begin{array}{c}\text { Спектральные } \\
\text { коэффициенты }\end{array}$} & \multicolumn{6}{|c|}{ Исследуемые нефти } \\
\cline { 2 - 9 } & YuT & Vch & Ger & Mam & Svt & Vh & VEg \\
\hline $\mathrm{C}_{1}\left(\mathrm{D}_{1610} / \mathrm{D}_{725}\right)$ - ароматики & 0.25 & 0.4 & 0.5 & 0.7 & 0.6 & 0.8 & 0.57 \\
\hline $\begin{array}{l}\mathrm{C}_{2}\left(\mathrm{D}_{745} / \mathrm{D}_{1465}\right) \text { отношение производных } \\
\text { бензола и метиленовой группы }\end{array}$ & 1.64 & 1.49 & 1.4 & 1.0 & 1.0 & 0.90 & 0.92 \\
\hline $\begin{array}{l}\mathrm{C}_{3}\left(\mathrm{D}_{1610} / \mathrm{D}_{1465}\right) \text { отношение аренов и ме- } \\
\text { тиленовой группы }\end{array}$ & 0.07 & 0.09 & 0.1 & 0.1 & 0.1 & 0.21 & 0.09 \\
\hline $\begin{array}{l}\mathrm{C}_{4}\left(\mathrm{D}_{965} / \mathrm{D}_{725}\right) \text { отношение нафтеновых и и } \\
\text { парафиновых групп }\end{array}$ & 0.50 & 0.19 & 0.4 & 0.4 & 0.36 & 0.48 & 0.37 \\
\hline $\mathrm{C}_{\mathrm{p}}\left(\mathrm{D}_{1377} / \mathrm{D}_{1465}\right)$ - разветвленности & 0.63 & 0.58 & 0.57 & 0.55 & 0.55 & 0.51 & 0.51 \\
\hline $\mathrm{C}_{\mathrm{o}}\left(\mathrm{D}_{1710} / \mathrm{D}_{1465}\right)-$ окисленности. & 0.12 & 0.03 & 0.06 & 0.06 & 0.04 & 0.09 & 0.03 \\
\hline
\end{tabular}

Table 3 .

Физико-химические свойства нефтей и эмульсий

\begin{tabular}{|c|c|c|c|c|c|c|c|c|}
\hline \multirow{2}{*}{ Параметры } & \multicolumn{8}{|c|}{ Образцы нефтей } \\
\hline & YuT & Vch & Ger & Svt & Mam & VEg & $\mathrm{Vh}$ & декан \\
\hline \multicolumn{9}{|c|}{ Физико-химические свойства нефтей } \\
\hline $\mathrm{T}^{\circ} \mathrm{C}$ & -30 & -43 & +6 & -16 & -5 & -13 & -15 & -30 \\
\hline плотность, $\mathrm{k} \Gamma / \mathrm{M}^{3}$ & 816 & 858 & 863 & 842 & 841 & 834 & 879 & 730 \\
\hline вязкость, $\mathrm{mPa}_{*} \mathrm{~s}$ & 6.13 & 19,3 & 25,1 & 17.5 & 30.3 & 23.1 & 22.7 & 0.8 \\
\hline \multicolumn{9}{|c|}{ Физико-химические свойства эмульсии воды в нефти $(\mathrm{B} / \mathrm{H})$} \\
\hline 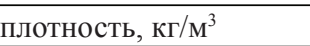 & 908 & 919 & 931 & 890 & 890 & 880 & 930 & - \\
\hline вязкость, $\mathrm{mPa}_{*} \mathrm{~s}$ & 109 & 184.9 & 130.8 & 25.17 & 45.54 & 7.49 & 12.92 & - \\
\hline $\begin{array}{l}\text { Площадь контакта } \\
\text { вода-орган. фаза, } \mathrm{m}^{2} / \mathrm{g} \\
\text { эмульсии }\end{array}$ & 0.035 & 0.202 & 0.337 & 0.197 & 0.223 & 0.128 & 0.258 & 0.066 \\
\hline
\end{tabular}

Отмечено, что вязкость и плотность приготовленных водонефтяных эмульсий значительно отличается от нативных нефтей. Согласно этому признаку, все образцы эмульсий делятся на 3 группы. Первая групп нефтей (YuT, Vch, Ger) образует эмульсии, вязкость которых по сравнению 
с нативной нефтью увеличивается от 5 до 18 раз, максимально для нефти YuT (табл. 3). Во второй группе (Svt, Mam) вязкости эмульсий возрастают, но в меньшей степени, примерно в 1.5 раза, в третьей группе (VEg, Vh ), напротив, происходит снижение вязкости в 1.7-3.0 раза. Пониженная вязкость по сравнению с исходной нефтью говорит об образовании прямой эмульсии нефти в воде $(\mathrm{H} / \mathrm{B})$. При образовании обратной эмульсии $(\mathrm{B} / \mathrm{H})$, её вязкость оказывается выше вязкости нативной нефти. Общим для образцов первой группы нефтей является повышенные значения вязкости эмульсий, показателя коэффициента разветвленности Сp, и низкие значения коэффициента ароматичности $\mathrm{C}_{1}$.

У образцов третьей группы, где вязкость полученной эмульсии ниже вязкости нативной нефти, значения Ср-минимальны, $\mathrm{C}_{1}$-неоднозначны.

Единственный положительный эффект образования гидрата метана получен в эксперименте с нефтью YuT. При нагревании образцов YuT во всех случаях регистрировались эндотермические эффекты, соответствующие плавлению льда.

\section{Заключение}

Из семи исследованных образцов нефтей - ҮuТ проявила способность к нуклеации и образованию газогидратов. В заключении можно выделить ряд характеристик YuT, способных сформировать систему гидратных частиц: минимальная плотность и вязкость, низкая ТЗ, высокое содержание смол, максимальное увеличение (в 18 раз) вязкости эмульсии по отношению к нативной нефти. Нефть ҮuT, в сравнении с другими исследуемыми нефтями, максимально биодеградирована с накоплением продуктов метаболизма, в том числе карбоновых кислот (п.п. $1700 \mathrm{~cm}^{-1}$ ), оказывающих положительное влияние на процессы нуклеации. Отметим, что площади контакта вода - органическая фаза для YuT меньше, чем для всех остальных нефтей (табл. 3). Это показывает, что скорость нуклеации в общем случае не пропорциональна этой площади.

Работа выполнена при финансовой поддержке гранта РНФ 17-1701085 2017-2019 2.2. "Кинетика образования и диссощиаџии газовых гидратов в нефтяных средах»

\section{Список литературы / References}

1. Sloan E.D., Koh C.A. Clathrate hydrates of natural gases. 3rd edition. London, New-York: CRC Press, Boca Rator, 2008. 731 p. 
2. Sloan E.D. Hydrate engineering / Ed. by J.B. Bloys. Richardson, Texas, 2000. V.21. $89 \mathrm{p}$.

3. Sum A.K., Koh C.A., Sloan E.D. A comprehensive view of hydrates in flow assurance: past, present and future // Proc. of the 8th International Conference on Gas Hydrates (ICGH 2014). Beijing, China, 2014.

4. Aizenberg J., Black A.J., Whitesides G.M. Control of crystal nucleation by patterned self-assembled monolayers // Nature. 1999. V. 398, pp. 495-498.

5. Wilson P.W., Lu W., Xu H., Kim P., Kreder M.J., Alvarenga J., Aizenberg J. Inhibition of ice nucleation by slippery liquid-infused porous surfaces (SLIPS) // Phys. Chem. Chem. Phys. 2013. V. 15, pp. 581-585.

6. Hammerschmidt E.G. Formation of Gas Hydrates in Natural Gas Transmission Lines // Ind. Eng. Chem. 1934. V. 26, №8, pp. 851-855.

7. Heneghan A.F., Moore H.J., Lee T.R., Haymet A.D.J. Statistics of heterogeneous nucleation of supercooled aqueous solutions in a self-assembled monolayer-coated container // Chem. Phys. Lett. 2004. V. 385, pp. 441-445.

8. Prasad P.S.R., Chari V.D., Sharma D.V.S.G.K., Murthy S.R. Effect of silica particles on the stability of methane hydrates // Fluid Phase Equilibr. 2012. V. 318, pp. 110-114.

9. Kashchiev D., Firoozabadi A. Nucleation of gas hydrates // J. Cryst. Growth. 2002. V. 243, №3-4, pp. 476-489.

10. Borgund A.E., Barth Tanja, Fotland P., Askvik K.M. Molecular analysis of petroleum derived compounds that adsorb onto gas hydrate surfaces // Applied Geochemistry 24 (2009), pp. 777-786.

11. Сваровская Л.И., Филатов Д.А., Гэрэлмаа Т., Алтунина Л.К. Оценка степени биодеструкции нефти методами ИК - и ЯМР Н-спектрометрии // Нефтехимия [Petrochemistry]. 2009. Т. 49. № 2. С. 153-158.

12. Salamat Y., Moghadassi A., Illbeigi M., Eslamimanesh A., Mohammadi A.H. Experimental study of hydrogen sulfide hydrate formation: Induction time in the presence and absence of kinetic inhibitor // J. Energ. Chem. 2013. V. 22, pp. 114-118.

13. Maeda N., Wells D., Hartley P.G., Kozielski K.A. Statistical analysis of supercooling in fuel gas hydrate systems // Energy Fuels. 2012. V. 26, pp. 1820-1827.

14. Ohmura R., Ogawa M., Yasuoka K., Mori Y.H. Statistical study of clathrate-hydrate nucleation in a water/hydrochlorofluorocarbon system: Search for the nature of the "Memory effect" // J. Phys. Chem. B. 2003. V. 107. P. 5289-5293.

15. Stoporev A.S., Manakov A.Y., Altunina L.K., Strelets L.A., \& Kosyakov V.I. Nucleation rates of methane hydrate from water in oil emulsions // Canadian Journal of Chemistry, (2015). 93(8), 882-887. 
16. Stoporev A.S., Manakov A.Y., Kosyakov V.I., Shestakov V.A., Altunina L.K., \& Strelets L.A. Nucleation of methane hydrate in water-in-oil emulsions: role of the phase boundary // Energy \& Fuels, (2016). 30(5), 3735-3741.

17. Zi M., Chen D., Ji H., Wu G. Energy Fuels 2016, 30, 5643-5650.

\section{ДАННЫЕ ОБ АВТОРАХ}

Сваровская Лидия Ивановна, старший научный сотрудник, кандидат биологических наук, доцент Федеральное государственное бюджетное учреждение науки Институт химии нефти Сибирского отделения Российской академии наук (ИХН СО РАН)

проспект Академический, 4, г. Томск, 634055, Российская Федераиия sli@ipc.tsc.ru

Манаков Андрей Юрьевич, заведующий лабораторией, доктор технических наук, профессор Федеральное государственное бюджетное учреждение науки Институт неорганической химии им. Сибирского отделения Российской академии наук (ИНХ СО РАН)

проспект Академика Лаврентьева, 3, г. Новосибирск, 630090, Российская Федерация

manakov@niic.nsc.ru

Алтунина Любовь Константиновна, заведующая лабораторией коллоидной химии нефти, доктор технических наук, профессор Федеральное государственное бюджетное учреждение науки Институт химии нефти Сибирского отделения Российской академии наук (ИХН СО РАН)

проспект Академический, 4, г. Томск, 634055, Российская Федераџия alk@ipc.tsc.ru

\section{DATA ABOUT THE AUTHORS}

Svarovskaya Lidiya Ivanovna, Senior Researcher, Candidate of Biology, Assistant Professor

Institute of Petroleum Chemistry, Siberian Branch of the Russian Academy of Sciences (IPC SB RAS)

4, Akademichesky Avenue, Tomsk, 634055, Russian Federation sli@ipc.tsc.ru 
Manakov Andrei Yurevich, Doctor of Technical Sciences, Professor

Institute of Inorganic Chemistry, Siberian Branch of the Russian Academy of Sciences (IPC SB RAS)

3, Akademica Lavrenteva Avenue, Novocibirsk, 630090, Russian Federation

manakov@niic.nsc.ru

Altunina Lubov Konstantinovna, Doctor of Technical Sciences, Professor Institute of Petroleum Chemistry, Siberian Branch of the Russian Academy of Sciences (IPC SB RAS)

4, Akademichesky Avenue, Tomsk, 634055, Russian Federation alk@ipc.tsc.ru 